\title{
External Fixator as Primary and Definitive Treatment of Closed Diaphyseal Lower Limb Fractures in Children
}

\author{
Bahaa Ali kornah ${ }^{1}$, Hesham Mohamed safwat ${ }^{2}$, Mohamed A Abdel AAl ${ }^{3}$, Nagy A Seleem ${ }^{4}$, Hesham Abdel Fattah \\ Mohamed $^{4}$ and Ehab A Alshal ${ }^{4}$
}

${ }^{1}$ Professor orthopedic surgery, Al Azhar University, Egypt

${ }^{2}$ Assistant Professor orthopedic surgery, Al-Azhar University, Egypt

${ }^{3}$ Consultant orthopedic surgery, El-bakry General Hospital, Egypt

${ }^{4}$ Lecturer orthopedic surgery, Al-Azhar University, Egypt

Submission: May 04, 2017; Published: June 02, 2017

*Corresponding author: Mohamed A Abdel-AAl, Consultant orthopedic surgery, El-bakry General Hospital, Ministry of Health, 61 Taha heussein, EL-Nozha El-gedida, Heliopolise Cairo, Egypt, E-mail: btmnail2010@hotmail.com

\section{Abstract}

Background: The target of fracture fixation is to stabilize bone till full healing and return of full function of injured extremity. The use of external fixation in lower extremity fractures of children usually reserved for open fractures especially in polytraumatized patients. In this study we tried to assess the effectiveness both clinical and radiological together with complications of using external fixators as a definitive tool of fracture fixation.

Patients and Method: We analyzed the outcomes and complications of 92 consecutive closed lower extremity long bone fractures in 82 children (52 males). All treated by closed manipulation and stabilization of fracture by one of three types of monoplane external fixators (Hoffman, dynamic axial fixators and tubuler fixator).

Results: 92 fractures in 82 children included this prospective study. Age range 5-14 years (average 7.6 years). Fixator applied for 6-9 weeks (average 8 weeks). Average follows up 21 months. Mean time for union 13 weeks (range 10 to 36 weeks). There were no cases of nonunion and low incidence of growth disturbances. All patients achieved a satisfactory outcome with little morbidity, early mobilization, and short period of hospitalization.

Conclusion: External fixator is a useful modality in treatment of pediatric closed diaphyseal fracture with multiple systemic injuries. It provides good stability can be done early or following surgical management of life threatening conditions, less invasive, avoids disturbance of fracture haematoma, inexpensive and many of its parts can be reused.

Keywords: External fixators; Children lower extremity fractures; Closed fractures

\section{Introduction}

The basic goal of fracture treatment is to stabilize the fractured bone to enable fast healing and return of full function of the injured extremity. For lower extremity fractures; stability is mandatory for weight bearing and for diaphyseal fractures, proper alignment of the fracture fragments is all that is needed for adequate function and prompt healing of the fracture. Nonoperative management is still treatment of choice for closed diaphyseal fractures in children [1,2]. This includes traction and plaster of Paris [3], closed reduction with pin in plaster or cast brace [4]. Surgery is indicated in: children with multiple trauma, severe soft tissue injuries, failed closed reduction and in cases where the reduction is difficult to be maintained as with cerebral palsy. Open reduction and internal fixation is an alternative tool used in those cases [5].

The use of external fixators became popular in the last twenty years with its availability and expertise who can apply them being popularized by the AO foundation. They had virtually supplanted the application of casts which had some complications and unpredictable outcomes and competed open reduction and internal fixation for its results with lower complication rate [6]. The aim of this work is to highlight and evaluate the use of external fixator in management of closed diaphyseal fracture of lower extremities in children and adolescents particularly with multitrauma patients. 


\section{Orthopedics and Rheumatology Open Access Journal}

\section{Patients and Methods}

The study was initiated after receiving approval from the institutional ethics committee for research in accordance with the ethical standards laid down in the 1964declaration of Helsinki and its later amendments. Also, a written consent had been obtained from the patient's parents or relatives for participating in the study. Between 2008 - 2014, Eight-Two patients (52 males and 30 females) were treated in the Al-Azhar University Hospitals. Age range (5-14 years) with an average 7.6 years. 4 patients had ipsilateral fractures (8 fractures), 3 had ipsilateral and contralteral limb fractures ( 9 fractures) and the rest of patients (75 patients) had single fracture either leg or femur. 18 had right femoral fractures, 12 left femoral fractures, 25 right tibial fractures and 20 left tibia. Inclusion criteria involved closed diaphyseal or metaphyseo-diaphyseal fractures of femur or tibia, patients between 5 to14years who did not receive conservative measures. Exclusion criteria involved patients below 5 years and above 14 years old, open fractures, pathological fractures and cases of non-union.

Among the causative trauma, direct traffic accidents were the most common ( 34 patients $41.5 \%$ ), indirect traffic accidents (11 patients $13.4 \%$ ) were inside the car not wearing seat belts, sports activities(15 patients $18.3 \%$ ), falling from a height (14 patients $17.1 \%$ ) and unknown causative trauma (8 patients 9.7\%). 21 patients (25.6\%) had associated injuries (Table 1). 8 patients had abdominal injuries, 4 had a combination of other bony injuries, 3 had multiple ribs fractures with chest injuries, 2 had a combination of chest and abdominal injuries, 2 had a combination of chest and head injuries, one patient had severe soft tissue injuries of lower limbs and One patient had head injury with soft tissue injuries of his four extremities.

Table 1: Showing the patients, their associated injuries and their management.

\begin{tabular}{|c|c|c|c|c|c|c|}
\hline Case No. & Age & Sex & Side & Bony Injuries & Associated injuries & Management of associated injuries \\
\hline 1 & 4 & M & Rt. & Femur & Abdominal trauma & Laparotomy and splenectomy \\
\hline 2 & 6 & M & Rt. & Femur & Abdominal trauma & Laparotomy and splenectomy. \\
\hline 3 & 5 & M & Rt. & Femur & Chest injury /head injury & Craniotomy, Chest tube \\
\hline 4 & 10 & $\mathrm{~F}$ & Rt. & Tibia/ Fibula & $\begin{array}{c}\text { Chest injury/head injury /skin } \\
\text { abrasion }\end{array}$ & $\begin{array}{c}\text { Chest injury /observation for head } \\
\text { injury./dressing }\end{array}$ \\
\hline 5 & 9 & M & Lt. & Tibia / Fibula & $\begin{array}{l}\text { Abdominal trauma /Multiple skin } \\
\text { lacerations }\end{array}$ & Laparotomy /dressing \\
\hline 6 & 4 & $\mathrm{~F}$ & Rt. & Femur & Pelvic fracture & External fixator for both \\
\hline 7 & 5 & M & Lt. & Tibia & Chest/Soft tissue injuries & Chest tube./dressing \\
\hline 8 & 11 & M & Rt. & Femur & $\begin{array}{l}\text { Severe soft tissue injuries to the } \\
\text { thigh and leg }\end{array}$ & Repeated debridement and dressing \\
\hline 9 & 12 & M & Rt. & Tibia/Fibula & Open fracture femur & $\begin{array}{l}\text { Debridement and external fixator for } \\
\text { both }\end{array}$ \\
\hline 10 & 14 & $\mathrm{~F}$ & Rt. & Femur & Head injury /soft tissue lacerations & Repeated dressing \\
\hline 11 & 7 & $\mathrm{~F}$ & Rt. & Femur & Abdominal injury & Laparotomy \\
\hline 12 & 9 & M & Lt. & Femur & $\begin{array}{l}\text { Rupture diaphragm /soft tissue } \\
\text { injuries }\end{array}$ & Repair /dressing \\
\hline 13 & 4 & M & Lt. & Tibia/ Fibula & Abdominal injury/soft tissue injuries & Laparotomy, liver repair/dressing \\
\hline 14 & 15 & M & Rt. & Femur & Chest injury & Thoracotomy/chest tube \\
\hline 15 & 14 & M & Rt. & Femur & Haemothorax & chest tube/exploration \\
\hline 16 & 13 & M & Lt. & Femur & Fracture pelvis & $\begin{array}{l}\text { external fixator for both femur and } \\
\text { pelvis }\end{array}$ \\
\hline 17 & 17 & M & Rt. & Femur & Abdominal injury & $\begin{array}{l}\text { Laparotomy and repair of a small tear } \\
\text { in the intestine }\end{array}$ \\
\hline 18 & 6 & M & Lt. & Femur & Chest /abdominal injuries & Chest tube/repair of a tear in the liver \\
\hline 19 & 4 & $\mathrm{~F}$ & Lt. & Femur & Abdominal injury & Laparotomy \\
\hline 20 & 8 & M & Lt. & Femur & Abdominal injury & Laparotomy \\
\hline 21 & 4 & $\mathrm{~F}$ & Rt. & Femur & $\begin{array}{l}\text { Forearm fractures/ soft tissue } \\
\text { injuries }\end{array}$ & $\begin{array}{c}\text { Laparotomy } \\
\text { POP forearm /dressing }\end{array}$ \\
\hline
\end{tabular}

Rt: Right side; Lt: Left side; M: Male; F: Female; Age: In years; POP: Plaster of Paris 


\section{Orthopedics and Rheumatology Open Access Journal}

\section{Surgical Technique}

General assessment of life threatening conditions together with local assessment of the fracture site and its stabilization requirements were first done for every patient. Dealing with life threatening injuries was done first followed by management of the fractures by the orthopedic surgeon. Preoperative prophylactic antibiotic (Cefazolin $\mathrm{Na}$ ) was administered. The operation began with the patient under general anesthesia and in the supine position in all cases. The surgical area was cleaned with an antiseptic (10\% povidone iodine solution) followed by closed reduction of the fracture under fluoroscopic control.

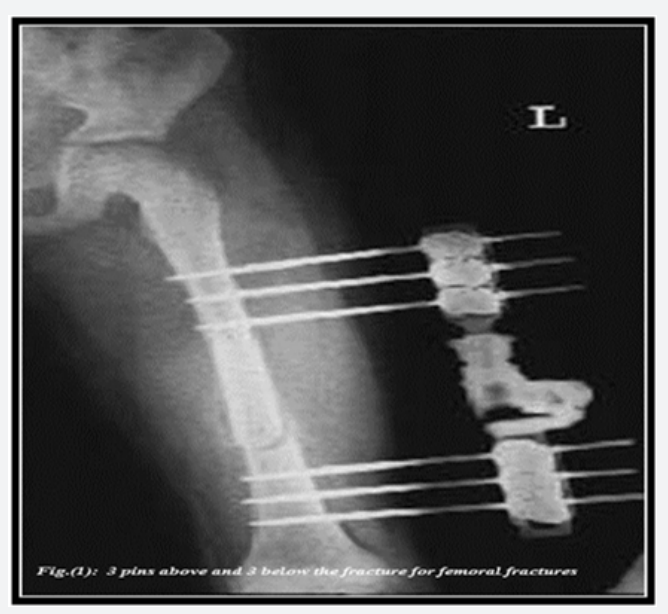

Figure 1: 3 Schanz pins above and 3 below the fracture for all femoral fractures.

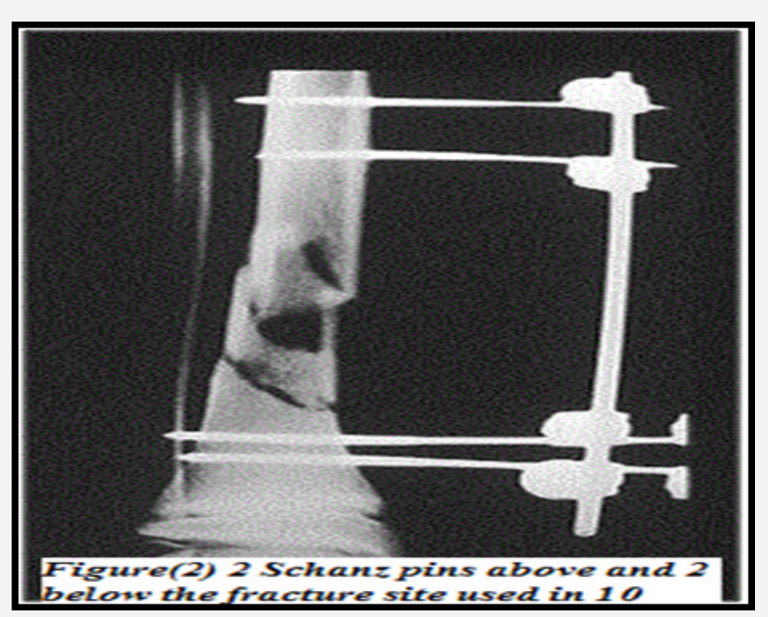

Figure 2: Schanz pins above and 2 below the fracture site used in 10 tibial fractures.

All fractures were stabilized with uniplanar External Fixation Set (Hoffman, dynamic axial fixators and tubuler fixator). The number of fixation pins placed in the fracture fragments depended upon the type of the fractures, age of the patients and the limb size. We utilized 3 partially threaded Stainless steel Schanz pins above and 3 below the fracture for all femoral fractures (Figure 1) and in most fracture tibia. While 2
Schanz pins above and 2 below the fracture site were used in 10 tibial fractures (Figure 2). They were inserted through skin stab incisions by a hand drill or a low speed power drill and in some cases insertion were preceded by pre drilling of the bone cortex and applying appropriate sleeve to protect the soft tissues.

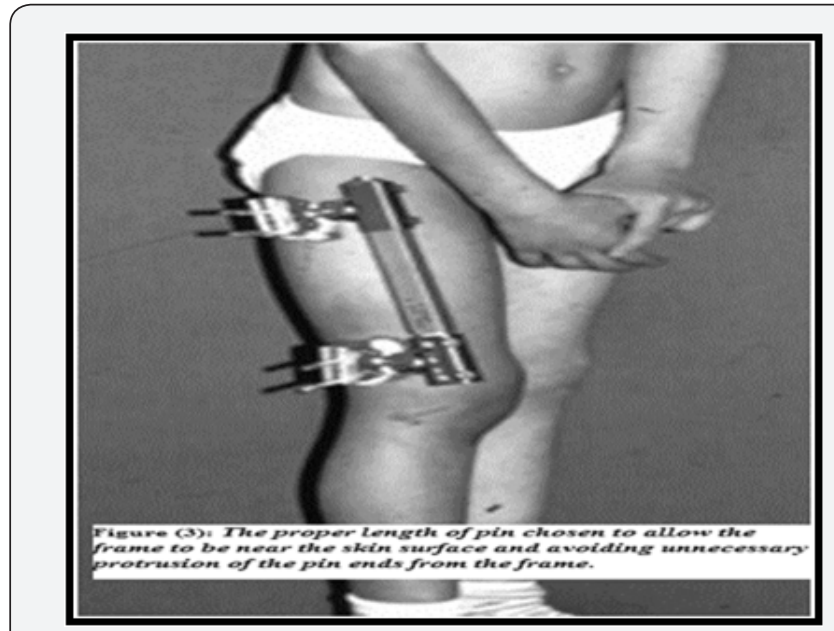

Figure 3: The proper length of pin chosen to allow the frame to be near the skin surface and avoiding unnecessary protrusion of the pin ends from the frame.

The proper length of pin was chosen to allow the frame of the fixators to be near the skin surface and avoiding unnecessary protrusion of the pin ends from the frame (Figure 3). Care was taken for insertion site to avoid injury to the growth plate. While applying the external fixator, closed manipulation of the fracture rechecked under C-Arm to achieve as near as possible an anatomical reduction. 46 fractures had been compressed at the time of operation. These fractures were transverse ones. No bone grafts or bone graft substitutes used in managing all the patients. After applying the fixator; range of motions (ROM) of the nearby joint was tested in every case. The pin tracts were sterilely covered and parenteral antibiotic therapy was continued for 72 hours postoperatively.

\section{Post Operative Regimen}

Applying a bulky wraps of dressings to control pin-skin motion. Daily cleansing and disinfection by saline and povidoneiodine to minimize pin-track infection. During hospitalization, parents received training on cleaning the fixator and the pin tracts. Passive and active joint motions were commenced on the first postoperative day as the patient could tolerate to prevent joint stiffness. Walking was allowed by crutches' support with partial or non-weight bearing once he or she became tolerable to bear weight on the involved extremity from the third postoperative day if the general condition permitted. This was followed by progressive weight bearing according to the progress of the fractures' healing. Cases of abdominal injuries were advised early mobilization to help early regaining of the intestinal motion. All patients were followed up clinically and 
radiologically, in the outpatient clinics after their discharging from hospitals. Radiographic examination was done weekly in the first month then every two weeks until complete union of fracture. The implants were removed when adequate union was established both clinical radiological during routine visits. After removal; the fracture was supported by either using crutches, cast braces or plastic splints. The average period for using the support was five weeks.

\section{Results}

Eighty-two children and adolescents (51 males and 31 females) with 92 closed consecutive lower extremity long bones fractures were treated. Three types of monoplanar external fixators had been used (Hoffman, dynamic axial fixators (Orthofix) and tubuler AO fixator). Time to surgery was $<12$ hours in $50(61 \%)$ patients, $12-24$ hours in $16(19.5 \%)$ patients, 1-3 days in $9(11 \%)$ patients and $>3$ days in $7(8.5 \%)$ patients. Average operative time 35 minutes (27- 55 minutes). Blood loss was minimal $(20-50 \mathrm{ml})$ and no blood transfusion was needed. Sixty-One patients $(74.4 \%)$ were ready to go home next day while Twenty-One cases (25.6\%) due to the presence of other injuries needing close observation and medical care maintained for a period in the hospital. Average hospital stay was 8.5 days (range 3-17 days).

The shortest time the external fixators remain fixed to the patient's limb was 12 weeks and the longest was 6 months (average time 8.6 weeks). The average follow up was 39 months (8-43 months). The mean time for union was 12 weeks with a range of 10 - 41 weeks. No cases of nonunion developed and only 4 cases (4.9\%) had delayed union. No clinically relevant malalignment cases. . Implants were removed after complete union of fracture had been assessed both clinical and radiological. The average time to implant removal 9.6 weeks (range 6-27 weeks). For implant removal, 37 patients (45.1\%) required sedation, while sedation was not required in 45 patients $(54.9 \%)$.

Sixty cases (73.2\%) showed no complications during followup period. Re-reduction performed in 4 patients $(4.8 \%)$ after loss of position. Seven cases $(8.6 \%)$ showed pin track infection but no single case showed deep bone infection. Refracture observed in two patients $(2.4 \%)$. Nine cases $(11 \%)$ showed leg length discrepancy of the affected side. Five cases showed limb lengthening with mean length of $1.3 \mathrm{~cm}$. (3 cases with $1 \mathrm{~cm}$, 1 case with $1.5 \mathrm{~cm}$ and 1 case with $2 \mathrm{~cm}$ lengthening). Four cases showed leg shortening with a mean shortening of $2 \mathrm{~cm}$. No patients had implant failure and no technical complications occurred during or after the operations. Range of motions of the hip joint in femoral shaft fracture was not limited but that of the knee was limited in the last 10 degrees in 4 cases and full ROM was regained within twelve weeks from the removal of the fixator. In fracture of the leg, the ROM of the knee was not limited and that of ankle joint was limited mainly in dorsiflexion in 3 cases and full ROM was regained within ten weeks.

\section{Discussion}

Closed fracture of long bones of lower extremity in children seldom requires open reduction and fixation $[7,8]$. In this study, the external fixator was used in management of 92 closed fractures of the lower limbs in 82 patients. Twenty-one had associated visceral and musculoskeletal injuries (Table 1). Mechanism of injury was mostly due to direct trauma by vehicles in RTAs and this type of trauma is commonly associated with other injuries in the body so that the use of Plaster of Paris (POP) in this situation makes the treatment of the other bony, soft tissue or visceral injuries difficult and in hot climates of the Middle East; hip spica or cast is uncomfortable to the patient (Figure 4). Also; traction as another way of treatment is not economic as it needs a long period of hospitalization and transportation is difficult. Pin and plaster had been used but still require good reduction $[4,9,10]$. The disadvantages of conservative treatment may include prolonged hospital stay, reduction loss, joint stiffness due to immobilization, difficulty of family and child compliance with treatment, and difficulty of cast care [11]. Open reduction and fixation is the alternative in those cases [7]. Sharrard [12] stated that open reduction and internal fixation is applicable in adolescence and requires an average stay of ten days (long hospital stay) which may cause some complications.

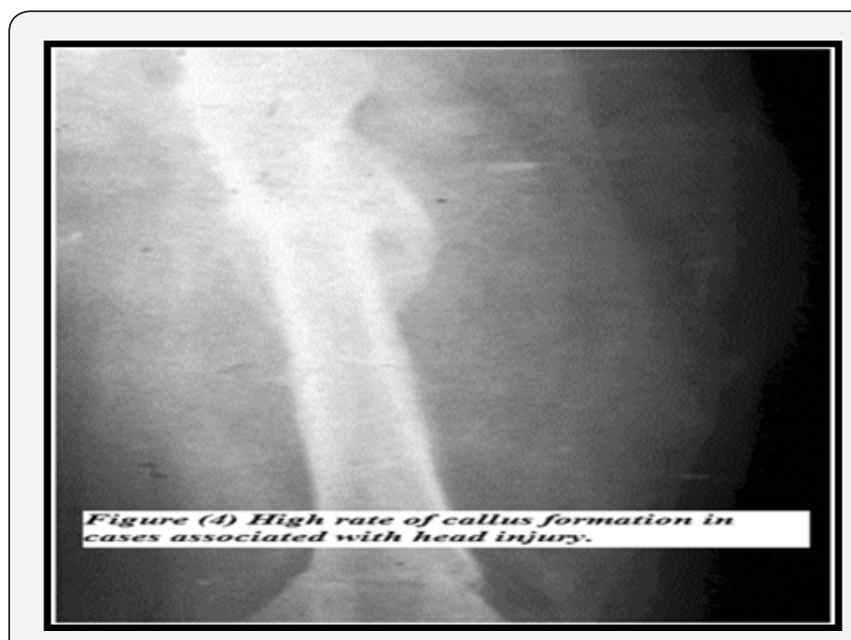

Figure 4: High rate of callus formation in cases associated with head injury.

Blood transfusion is often necessary and the child needs nursing care for psychological stress. Also; a second operation is needed to remove the metal. In our study; we utilized external fixators as a definitive tool of treatment in 92 fractures. External fixators carries the following advantages: immediate fracture stabilization which is difficult to achieve by cast splinting in multiple injured children, a short period of anesthesia needed so; it would be feasible following surgical management of life threatening conditions, easy physiotherapy, easy wound care, capability to perform shortening and lengthening in the same set and avoidance of complications of open reduction $[12,13]$. However; some shortcomings may follow the use of fixators 
as some complications in the soft tissues at pin site insertion, iatrogenic vascular lesions, pins tract infections, iatrogenic fractures and these can be avoided by sticking to the principles of external fixator application and careful attention and care to pin site insertion [14].

The mean operation time was 35 minutes (range, 27-55 minutes) and the total intraoperative fluoroscopic control duration was 1.1 minutes. Weinberg et al. reported mean operation time 66 minutes and the mean length of fluoroscopic control was 1.2 minutes [15], El Hayek et al. [12] reported 55 minutes for operative time and 1.8 fluoroscopic controls duration [12]. Beltsios et al. [14] recrorded50 minutes a mean operative time [14]. The difference is related to steeping of learning curve with experience and localization of fractures. Regarding hospital stays Weinberg et al. [15] reported means length of hospital stay 5.1 days while Wallace et al. [15] reported 9.1 days for 30 pediatric patients who were treated with external fixator and Aranson et al. [16] reported in their study a mean length of hospital stay of 6.9 days in 139 patients with femoral shaft fractures. In the current study, the mean length of hospital stay was 8.5 days (range, 3-17 days).

The mean time for bone consolidation in our study was 12 weeks with a range of $(10-41)$ weeks. Krettek et al. [8] mentioned that average time for union in their study was 12 weeks, which is similar to the results obtained in our study. No cases of non union observed in our study similar to the study of Blasier et al. [17] in their patients treated with external fixators. The high rate of union in our series might be due to the fact that all injuries are closed and the minimal invasive interference so; there is no disturbance of the fracture haematoma. There are two cases with a high rate of callus formation and these cases are associated with head injury (Figure 5).

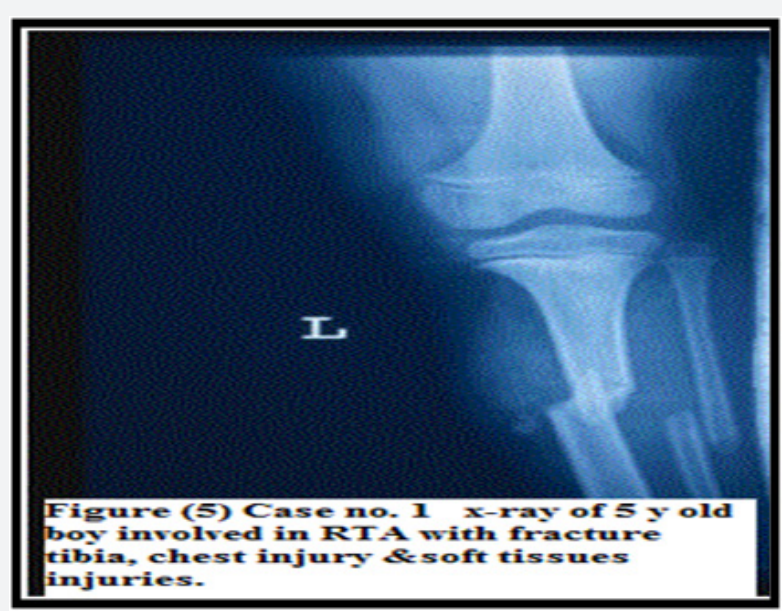

Figure 5: Case no. 1: A radiography of a 5 years old boy, who was involved in RTA with fracture tibia, chest injury and soft tissues injuries.

Angulation values lower than 15 degrees are not clinically significant and values between 10-25 degrees can be tolerated during the recovery; however, angulations of 25 degrees require surgical correction [18]. There were no cases of clinically significant malunionin in our series and this may be attributed to proper reduction achieved in most cases and the feasibility to correct any deformity owing to easiness to manipulate the fixators during early stages of union [19].

There was a low incidence of growth changes which had been evaluated both clinical and radiological via standardized orthograms. Krettek et al. [8] advocated that precise anatomical reduction should be carried out to avoid bony growth disturbance. In the presenting study; the reduction in a satisfactory position and alignment with stabilization until healing occurs, ended with good results and minimal growth disturbance. This minimal growth disturbance was compensated as the child grew over the following months. The refracture rate was 3\% in the study by Weinberg et al. [15] and $2.9 \%$ in the study by Aranson et al. [16]. The fact that the implant was removed after 40 days and refracture occurred within one week of implant removal suggested that early implant removal and non use of protective support significantly increased the re-fracture risk [2]. In our study, no single case showed refracture after bony union and this might be attributed to using of a protective support after removal of the external fixators (Figures 6A \& 6B).

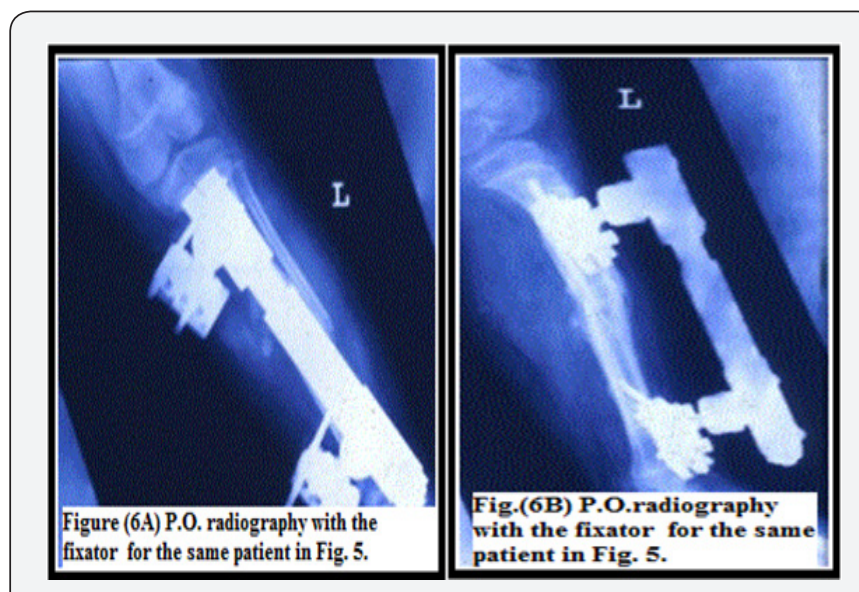

Figure 6A \& 6B: A postoperative radiography with the external fixator for the same patient in Figure 5.

One of the causes of lack of popularity of external fixators' usage is incidence of pin tract infection [20]. In a series of 191 patients with external fixation lasting for $<28$ days, pin site infection rate was $3.7 \%$ while those patients whose external fixators lasted longer than 28 days, the rate was 22\% [21] (Figures 7-9). Weinberg et al. [15] reported a rate of pin tract infections of $7.4 \%$ in 121 pediatric femoral fractures while Blasier et al. [17] reported $36 \%$ in 139 patients. In the current study, seven cases $(8.6 \%)$ showed pin track infection but no single case showed deep bone infection [22,23]. All cases were recovered with oral antibiotherapy. The low rate of pin infection may be attributed to the good care of pin site insertion either by nurses, patient himself or the parents (Figures $10 \& 11$ ). 


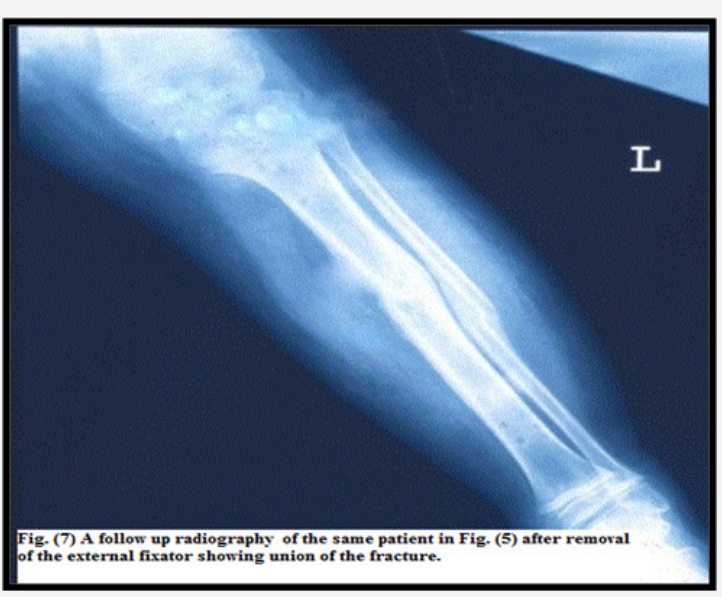

Figure 7: A follow up radiography of the same patient in Figure 5 after removal of the external fixator showing union of the fracture.

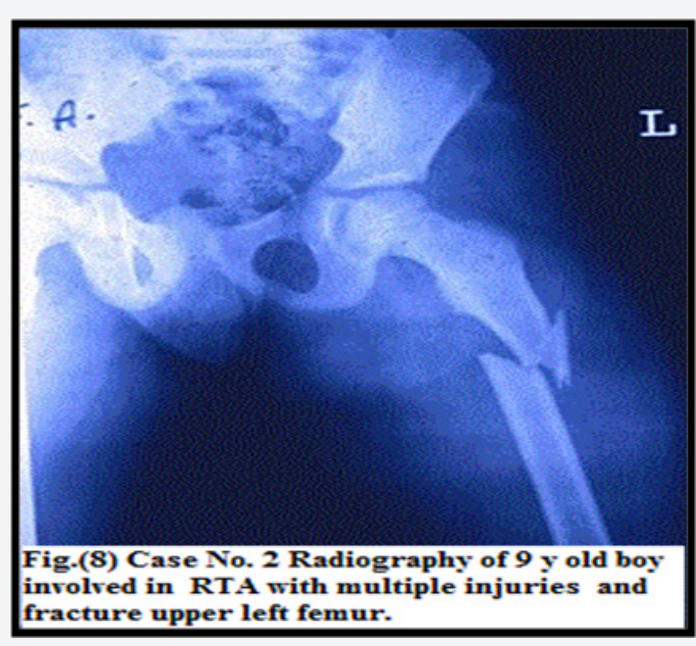

Figure 8: Case No. 2: Radiography of 9 years old boy involved in a RTA with multiple injuries and fracture upper left femur.

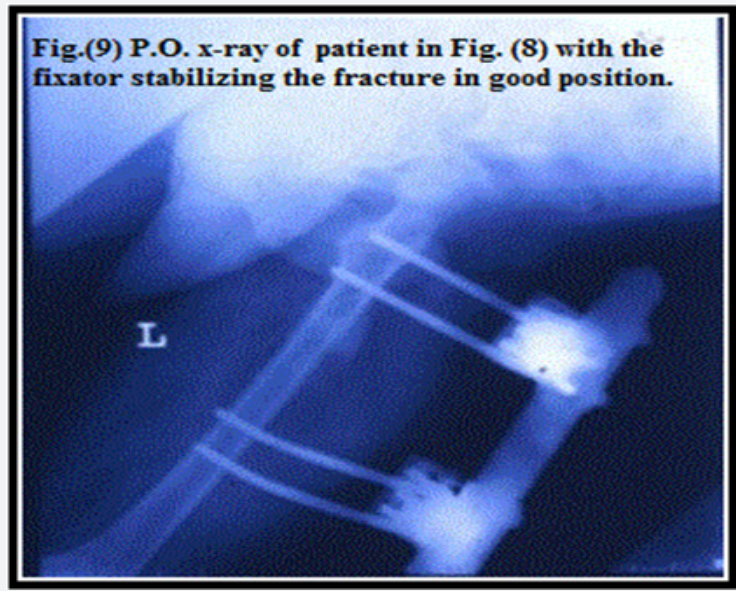

Figure 9: A post operative radiography of the same patient in Figure 8 With the external fixator stabilizing the fracture in good position.

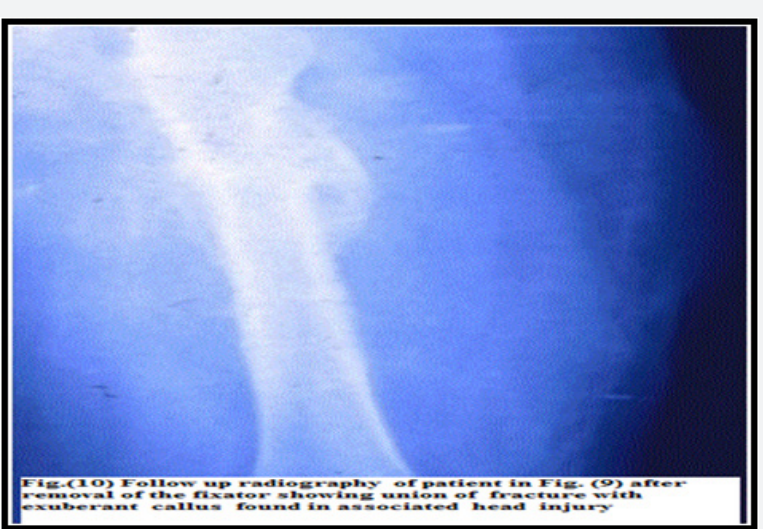

Figure 10: A follow up radiography of the same patient in Figure 9 after removal of the external fixator showing union of the fracture with the exuberant callus formation which is found in associated head injury.

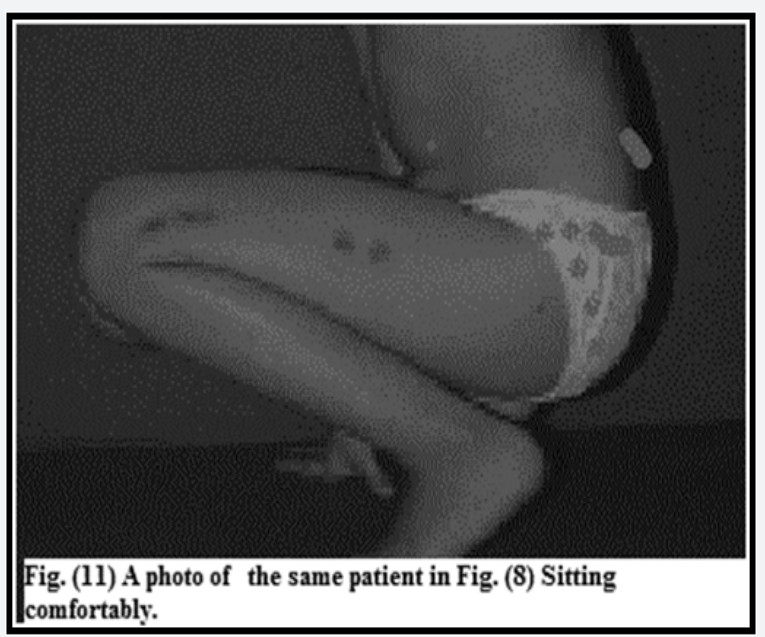

Figure 11: A photo of the same patient in Figure 8 Sitting comfortably.

\section{Conclusion}

The external fixator is a useful modality in treatment of closed diaphyseal fracture in children and adolescents with multiple systemic injuries. The advantages compared with nonsurgical treatment include providing good stability, less invasive ,well tolerated, inexpensive, causes less morbidity' shorter hospital stay, early mobilization, avoids disturbance of fracture haematoma and is cosmetically acceptable in addition to rapid child and family compliance, early return to school, short surgical learning curve. We believe that the advantages far outweigh the disadvantages.

\section{References}

1. Heyworth BE, Galano GJ, Vitale MA, Vitale MG (2004) Management of closed femoral shaft fractures in children, ages 6 to 10: national practice patterns and emerging trends. J Pediatr Orthop 24(5): 455459.

2. Krettek C, Hass N, Walkery T, Scheine H (1991) Treatment of femoral 
shaft fractures in children by external fixation. Injury 22(4): 263-266.

3. Buehler KC, Thompson JD, Sponselle, PD, Black BE, Buckley SL (1995) A Prospective Study of Early Spica Casting Outcomes in the Treatment of Femoral Shaft Fractures in Children. Journal of Pediatric Orthopaedics 15(1): 30-35.

4. Scott J, Wardlaw D, McLauchlan J (1981) Cast bracing of the femoral shaft fractures in children :a preliminary report. J Pediatr Orthop 1(2): 199-201.

5. Spiegel PG, Mast JW (1980) Internal and external fixation of fractures in children. Orthop Clin North Am 11(3): 405-421.

6. Alonso JF, Horowitz M (1987) Use of the AO/ASIF external fixation in children. J Pediatr Orthop 7(5): 594-600.

7. Helenius I, Lamberg TS, Kaariainen S, Impinen A, Pakarinen MP (2009) Operative treatment of fractures in children is increasing. A populationbased study from Finland. J Bone Joint Surg Am 91(11): 2612-2616.

8. Sharrerd WJW (1991) Pediatric Orthopeadic and fractures. ( $3^{\text {rd }}$ edn), Blackwell scientific publication, Oxford, UK, pp. 1440-1515.

9. Guttmann GG, Simon R (1988) Three-point fixation walking spica cast: an alternative to early or immediate casting of femoral shaft fractures in children. J Pediatr Orthop 8(6): 699-703.

10. Aronson DD, Singer RM, Higgins RF (1987) Skeletal traction for fractures of the femoral shaft in children. A long-term study. J Bone Joint Surg Am 69(9): 1435-1439.

11. Jauquier N, Doerfler M, Haecker FM, Hasler C, Zambelli PY (2010) Immediate Hip Spica Is as Effective as, but More Efficient than, Flexible Intramedullary Nailing for Femoral Shaft Fractures in Pre-School Children. J Child Orthop 4(5): 461-465.

12. Haikewych G (2002) Temporary external Journal fixation for the management of complex intra- and periarticular fractures of the, lower extremity. J Orthop Trauma16: 678-685.
13. El Hayek T, Daher AA, Meouchy W, Ley P, Chammas N, Griffet J (2004) External fixators in the treatment of fractures in children. J Pediatr Orthop 13(2): 103-119.

14. Beltsios M, Savvidou O, Kovanis J, Alexandropoulos P, Papagelopoulos $P$ (2009) External fixation as a primary and definitive treatment for tibial diaphyseal fractures. Strategies Trauma Limb Reconstr 4(2): 8187.

15. Weinberg AM, Leitner A, Lampert C, Laer L (2000) External Fixation of Pediatric Femoral Shaft Fractures: Treatment and Results of 121 Fractures. European Journal of Trauma 26(1): 25-32.

16. Hedin H, Hjorth K, Rehnberg L, Larsson S (2003) External fixation of displaced femoral shaft fractures in children: a consecutive study of 98 fractures. J Orthop Trauma 17(4): 250-256.

17. Aronson J, Tursky EA (1992) External fixation of femur fractures in children. J Pediatr Orthop 12(2): 157-163.

18. Blasier RD, Aronson J, Tursky EA (1997) External fixation of pediatric femur fractures. J Pediatr Orthop 17(3): 342-346.

19. Loder RT, O Donnell PW, Feinberg JR (2006) Epidemiology and mechanisms of femur fractures in children. J Pediatr Orthop 26(5): 561-566.

20. Wallace ME, Hoffman EB (1992) Remodelling of angular deformity after femoral shaft fractures in children. J Bone Joint Surg Br 74(5): 765-769.

21. Kesemenli CC, Subasi M, Arslan H, Tuzuner T, Necmioglu S, et al. (2004) Is external fixation in pediatric femoral fractures a risk factor for refracture? J Pediatr Orthop 24(1): 17-20.

22. Davies R, Holt N, Nayagam S (2005) The care of pin sites with external fixation. J Bone Joint Surg Br 87(5):716-719.

23. Parameswaran AD, Roberts CS, Seligson D, Voor M (2003) Pin site infection with contemporary external fixation: how much of a problem? J Orthop Trauma 17(7): 503-507.

\section{Your next submission with Juniper Publishers will reach you the below assets}

- Quality Editorial service

- Swift Peer Review

- Reprints availability

- E-prints Service

- Manuscript Podcast for convenient understanding

- Global attainment for your research

- Manuscript accessibility in different formats

( Pdf, E-pub, Full Text, Audio)

- Unceasing customer service

Track the below URL for one-step submission https://juniperpublishers.com/online-submission.php 